\title{
Effect of Different Growth Regulators on Soybean (Glycine max L.) Regeneration
}

\author{
B.U. Rathod ${ }^{1 *}$, N.R. Dattagonde ${ }^{2}$, M.P. Jadhav ${ }^{1}$ and P.P. Behre ${ }^{2}$ \\ ${ }^{1}$ Department of Biotechnology, University of Agricultural Sciences, Dharwad, Karnataka, India \\ ${ }^{2}$ Department of Crop Science, Mahatma Gandhi College of Agricultural Biotechnology, \\ Nanded, Maharashtra, India \\ *Corresponding author
}

\section{A B S T R A C T}

\begin{tabular}{|c|}
\hline Keywords \\
\hline $\begin{array}{l}\text { Soybean, } \\
\text { Regeneration, 2,4-D, } \\
\text { BAP, IBA. }\end{array}$ \\
\hline Article Info \\
\hline $\begin{array}{l}\text { Accepted: } \\
\text { 20 September } 2017 \\
\text { Available Online: } \\
10 \text { November } 2017\end{array}$ \\
\hline
\end{tabular}

In present study efforts were made to improve the regeneration protocol in the popular local soybean cultivars MAUS-71 and MAUS-162. Embryonic axis and Cotyladory node explants were taken and inoculated on different concentration of 2,4-D. Among those MS6D media containing 6mg/L 2,4-D were give best response for callus initiation. After proper callus formation these explants were transferred to shoot initiation and multiplication medium containing different concentration of BAP. MS media fortified with $3 \mathrm{mg} / \mathrm{L}$ BAP (MS3B) shows maximum shoot initiation and multiplication results. The Cotyladory node explants of cv. MAUS-71 shows maximum growth and development in all three types of media for all types growth conditions. The MS media fortified with 0.3 $\mathrm{mg} / \mathrm{L} \mathrm{IBA}$ as growth regulators gives better results for root formation in both types of explants and in both cultivars.

\section{Introduction}

Soybean (Glycine max L.) is a legume crop belongs to family leguminosae. It is one of the important food and feed crop throughout the world. It provides oil as well as protein to the living beings. Soybean oil is used for making human food products and cooking oil and has numerous industrial applications including soaps, oils, paints, cosmetics, plastics, clothing, and solvents. Recently, soybean is also used as biofuel crop to meet global energy demands putting significant pressure on crop production for food. Moreover, global climate change presents threats to our food supply.
Soybean is second most cultivated oilseed crop in India after ground nut. As most of the soybean cultivated area in India come under rained condition it suffers from the problem of the water scarcity. Drought stress affects all stages of plant growth and consequently reduces the crop yield (Manavalan et al., 2009). An effort has been made using classical breeding approaches to develop the disease (Khanh et al., 2013) and pest resistant varieties (Dar et al., 2006) but due lack of resources, none of the drought resistant variety has been developed yet in India. As the transformation techniques are well 
familiar, there is opportunity to develop the drought resistant varieties but efficient regeneration protocol is one of the main prerequisite for it. Although some of the transformation studies have been carried out but the transformation efficiency is less due to less regeneration percentage (Hinchee $e t$ al., 1988; Yan et al., 2000; Zeng et al., 2004; Paz et al., 2004;).

Few efforts have been made to develop the regeneration protocol in soybean cultivars (Kumari, et al., 2006; Loganathan et al., 2010). Regeneration efficiency may vary with genotype varies due to their physiological variability (Park et al., 2004). Germination efficiency also plays an important role in improving regeneration, but may be restricted due to dormancy and poor germination of seeds. However, that limitation can be overcome by using optimal media. Regeneration mainly depends on growth hormone concentration and explants source, because each explants gives different response to the different plant growth regulators concentration.

In present investigation we standardized the regeneration protocol for the cultivars MAUS 71 and MAUS 162 which are considered to be good cultivars in the Maharashtra. However, no previous studies have been performed to standardize regeneration protocols using these two cultivars.

\section{Materials and Methods}

The commercial Local cultivars of Soybean 'MAUS-71 and MAUS-162' are well famous and accepted varieties in Maharashtra and some of the North eastern states with yield ( $\mathrm{Kg} / \mathrm{ha}$ ) 2000 to 2500 , were selected for the present study. Seeds were obtained from the 'Krishi Vigyan Kendra, Pokharni, Nanded'. Initially Soybean seeds were washed with tween-20 for 20 min and rinsed with distilled water 8-9 times. Further sterilization $70 \%$ ethanol for $2 \mathrm{~min}$ followed by $0.5 \% \mathrm{HgCl}_{2}$ solution for $5 \mathrm{~min}$ was carried out inside the laminar air flow chamber. Finally, seeds were soaked in sterile water for 1-2 min prior to inoculation in to MS medium without any growth regulator. After germination embryonic axis and cotyladory nodes were removed from the imbibed seed coat and placed on MS medium with different combinations of growth regulators as mentioned in Table 1 (Fig. 1). Plates were incubated at $25^{\circ} \mathrm{C}$ in dark. For the study of effect of growth regulators on regeneration, embryogenic part of the callus was cut into small pieces approximately $2-3 \mathrm{~mm}$ in size and inoculated on MS fortified with different concentration of auxins and cytokinins and incubated at $25^{\circ} \mathrm{C}$ in a $16 \mathrm{~h}$ light and $8 \mathrm{~h}$ dark photoperiod. Firstly inoculated the explants in MS media fortified with different concentration of 2,4-D for callus induction and then subculture on MS media fortified with different concentration BAP for shoot induction and multiplication studies. Small shoots $(2-3 \mathrm{~cm})$ were sub-cultured on MS media fortified with different concentration of IBA for study effects on root regeneration in growth chamber. For all explants cultures, observations were recorded at 3 stages of each callus initiation, shoot initiation and root induction.

\section{Results and Discussion}

The present study revealed with an objective to check the response of cotyledon node and embryonic axis explants of soybean to different concentrations of growth regulators. For study of soybean, mature seeds were sterilized, germinated and used for explants generation. For both explants we germinate the soybean seedlings in vitro on MS media without growth regulator. After germination they were used for isolation of embryonic axis and cotyladory node explants. Cotyladory 
nodes were observed to swell 5-10 days after plating. Callus formation was observed after 20-25 days of plating. Callus proliferation started from the lower portion of explants. After callus induction, initiated callus tissue developed distinct phenotypes viz. wet, rough, hard dense and glossy, greenish with different developmental potentials. After 4045 days of inoculation, calli could be distinguished on the basis of their phenotypic appearances. Compact, light green coloured calli with few or many dark green bead like structures and sometimes partially covered with thin layer of white loose callus were recognized as embryogenic calli. The callus induction from Embryonic axis cultures varied from $35 \%-70 \%$. Maximum callus induction was evident from MAUS-71 (70.0\%) followed by MAUS-162 (65.0\%). In terms of the culture media response to in vitro culture, the performance of culture media MS6D with 6mg/L 2,4-D (70\%) was found to be the best in terms of callus initiation (Fig. 1). It is reported that in case of soybean callus initiation 2,4-D gives the better results compare to the other growth regulators (Radhakrishnan and Ranjithakumari, 2007; Kumari, et al., 2006).

Table.1 Concentrations of plant growth regulators fortified with MS culture media for preliminary experiments

\begin{tabular}{|c|c|c|c|c|}
\hline \multirow{2}{*}{ Sr. No. } & \multirow{2}{*}{ Media } & \multicolumn{4}{|c|}{ Growth regulators (mg/L) } \\
\cline { 3 - 5 } & & $2,4-\mathrm{D}$ & BAP & IBA \\
\hline 1 & MS & 2.0 & - & - \\
\hline 2 & MS & 4.0 & - & - \\
\hline 3 & MS & 6.0 & - & - \\
\hline 4 & MS & - & 1.0 & - \\
\hline 5 & MS & - & 2.0 & - \\
\hline 6 & MS & - & 3.0 & - \\
\hline 7 & MS & - & - & 0.1 \\
\hline 8 & MS & - & - & 0.2 \\
\hline 9 & MS & - & - & 0.3 \\
\hline
\end{tabular}

Table.2 Observation on in vitro regeneration of Soybean cultivars

\begin{tabular}{|c|c|c|c|c|c|c|}
\hline \multirow{3}{*}{$\begin{array}{l}\text { Morphological } \\
\text { growth studied for }\end{array}$} & \multirow{3}{*}{ Media } & \multirow{3}{*}{$\begin{array}{l}\text { Concentration of different } \\
\text { growth regulators } \mathrm{mg} / \mathrm{L}\end{array}$} & \multicolumn{4}{|c|}{$\begin{array}{c}\text { No. of explants showing } \\
\text { morphogenic growth/20 explant }\end{array}$} \\
\hline & & & \multicolumn{2}{|c|}{ MAUS-71 } & \multicolumn{2}{|c|}{ MAUS-162 } \\
\hline & & & EA & $\mathrm{CN}$ & EA & $\mathrm{CN}$ \\
\hline \multirow{3}{*}{ Callus formation } & MS2D & 2,4-D $2 \mathrm{mg} / \mathrm{L}$ & 8 & 7 & 8 & 5 \\
\hline & MS4D & 2,4-D $4 \mathrm{mg} / \mathrm{L}$ & 12 & 13 & 11 & 10 \\
\hline & MS6D & 2,4-D $6 \mathrm{mg} / \mathrm{L}$ & 15 & 14 & 14 & 13 \\
\hline \multirow{3}{*}{$\begin{array}{l}\text { Shoot initiation and } \\
\text { multiplication }\end{array}$} & MS1B & BAP $1 \mathrm{mg} / \mathrm{L}$ & 7 & 5 & 6 & 4 \\
\hline & MS2B & BAP $2 \mathrm{mg} / \mathrm{L}$ & 10 & 9 & 7 & 8 \\
\hline & MS3B & BAP $3 \mathrm{mg} / \mathrm{L}$ & 14 & 12 & 10 & 11 \\
\hline \multirow{3}{*}{ Root initiation } & MS0.1I & IBA $0.1 \mathrm{mg} / \mathrm{L}$ & 7 & 5 & 5 & 4 \\
\hline & MS0.2I & IBA $0.2 \mathrm{mg} / \mathrm{L}$ & 10 & 8 & 7 & 8 \\
\hline & MS0.3I & IBA $0.3 \mathrm{mg} / \mathrm{L}$ & 13 & 12 & 10 & 11 \\
\hline
\end{tabular}

Note: EA- Embryonic Axis, CN- Cotyladory Node 


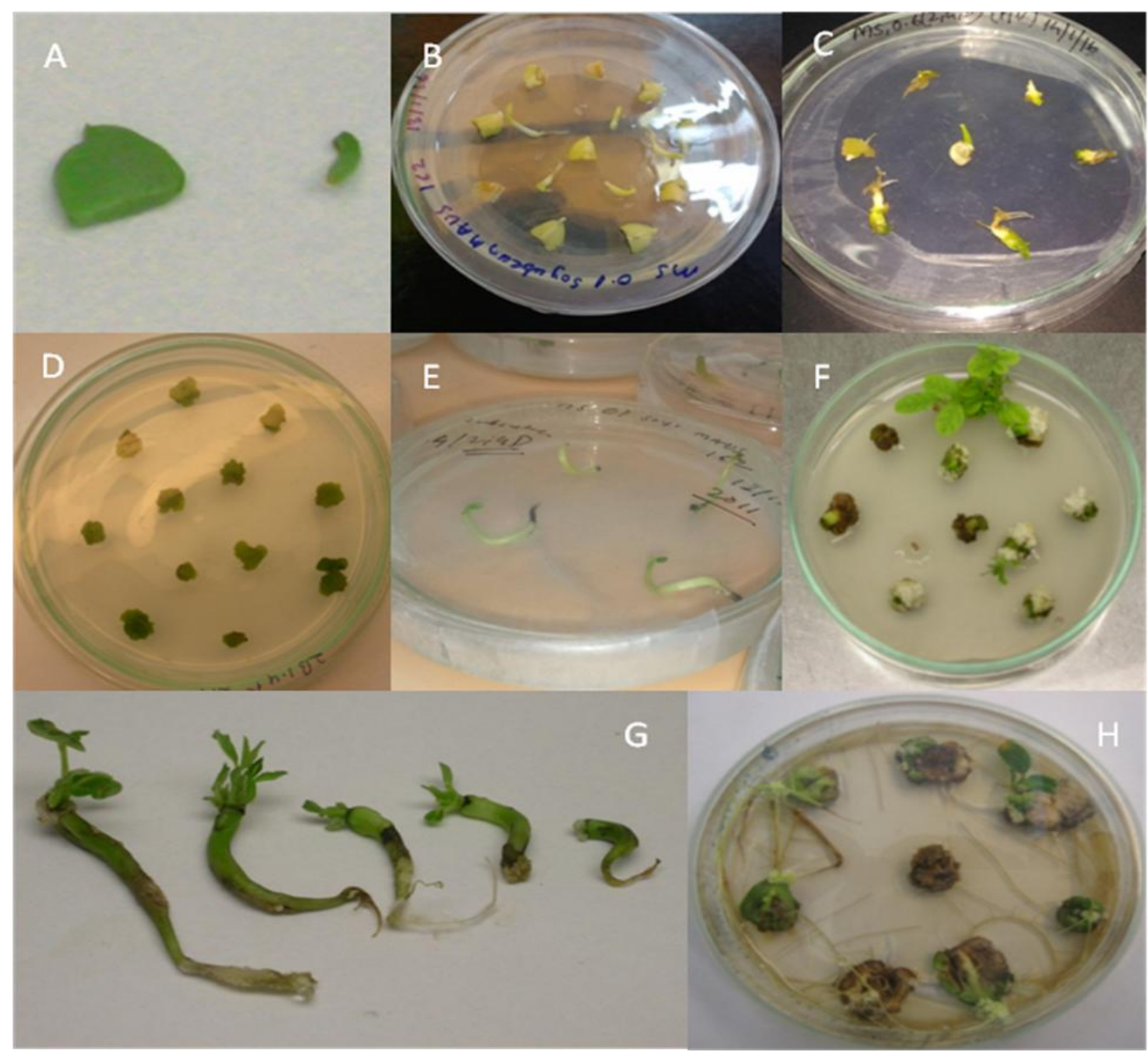

Fig. 1:- Different stages of regeneration of soyb ean explants.

A- Cotyladory node and Embryonic axis as explants, B-Inoculated Cotyladory Node and embryonic axis on basal MS media, C- Initiation of callus in Embryonic axis in 2,4-D media. D-Initiation of callus in Cotyladory Node in 2,4-D media, E- Single Shoot initiation in BAP media, F- Multiple shoot initiation in BAP, G-Root and shoots initiation in Embryonic axis Explants in IBA media, H-Root and shoots initiation in cotyla dory node explants IB A media

It is found that it gives the different responses for the various concentrations of the media (Kumari, et al., 2006; Loganathan et al., 2010). In our experiment, 2,4-D with its higher concentration of $6 \mathrm{mg} / \mathrm{l}$ initiated callus faster (within 2 weeks) than lower concentrations $(2 \mathrm{mg} / \mathrm{l})$. The callus initiation started from the lower portion of explants usually in contact with the culture medium. Callus initiating explants were counted on different concentration of 2,4-D. Variation in the percent callus formation was may be due to the genotypic difference of soybean cultivars. 
After callus induction from the explants, callus tissue developed distinct characteristics such as dense, rough, soft and sometimes glossy. These distinctness reflected diversity in in vitro developmental potentials with the different culture medium regimes.

In vitro morphogenesis, the way in which a callus forms a new plant in vitro, was variable. During the present investigation of checking response of different explants on different concentration of growth regulators on plant regeneration from the explants cultures appeared to be direct as well as via indirect (callus) phase. Culture media played an important role in the formation of morphogenic callus (Table 2).

After proper callus formation these explants were transferred to shoot initiation and multiplication medium containing different concentration of BAP. MS media fortified with $3 \mathrm{mg} / \mathrm{L}$ BAP (MS3B) shows maximum shoot initiation and multiplication results. The Cotyladory Node explants of cv. MAUS-71 shows maximum growth and development in all three types of media for all types growth conditions. The shoot initiation and multiplication from Embryonic axis cultures varied from 25\%-60\%. Among two accessions, maximum embryogenic calli formation, Shoot initiation and multiplication was observed for MAUS-71 (60\%) followed by MAUS-162 (55.0\%). In terms of the culture media response to in vitro culture, the performance of culture media MS3B (60.0\%) followed by MS2B (45.0\%) was found to be most responding for embryogenic callus formation, Shoot initiation and multiplication. These results are in agreement with the previous findings (Hiraga et al., 2007; Dan et al., 1998).

The MS media fortified with $0.3 \mathrm{mg} / \mathrm{L} \mathrm{IBA}$ as growth regulators gives better results for root formation in both types of explants and in both cultivars. The average mean roots formation from Embryonic axis cultures explants varied from 25\%-60\%. Maximum root formation was observed for cv. MAUS$71(60 \%)$ on MS0.3I media followed by MAUS-162 (55\%).

Here attempt has been made to develop a simple procedure to regenerate popular soybean cultivars MAUS-71 and MAUS-162 with the use of 2,4-D, BAP and IBA. All these different growth regulators were used for the various stages of the regeneration. This study revealed that Soybean plants can be produced by using these growth regulators with its proper concentrations. These findings will helpful to perform the genetic transformation study in the soybean cultivars.

\section{References}

Dan Y, and Reichert N A, (1998). Organogenic regeneration of soybean from hypocotyl explants. In Vitro Cellular \& Developmental BiologyPlant, 34:14-21.

Dar W D, Sharma H C, Thakur R P, Gowda, C L L, (2006). Developing varieties resistant to insect pest and diseases: An Eco-friendly Approach for Pest Management and Environment Protection. Crop Research and Environmental Challenges, 1-6.

Hinchee M A W, D V Conner-Ward, C A Newell, R E McDonnell, S J Sato, C S Gasser, D A Fischhoff, D B Re, R T Fraley, R B Horsch, (1988) Production of transgenic soybean plants using Agrobacterium-mediated DNA transfer. Nat. Biotechnol. 6: 915-922.

Hiraga S, Minakawa H, Takahashi K, Takahashi R, Hajika M, Harada K, Ohtsubo N, (2007). Evaluation of somatic embryogenesis from immature cotyledons of Japanese soybean cultivars. Plant Biotechnology 24:435- 
440.

Khanh T D, Anh T Q, Buu B C, Xuan T D, (2013). Applying molecular breeding to improve soybean rust resistance in Vietnamese elite soybean. American Journal of Plant Sciences, 4:01-1.

Kumari BDR, Settu A, Sujatha G (2006). Somatic embryogenesis and plant regeneration in soybean. Indian $J$. Biotechnol. 5: 243-245.

Loganathan M, Maruthasalam S, Shiu YL, Lien WC, Hsu WH, Lei PF, Yu CW, Lin CH. (2010) Regeneration of soybean (Glycine max L. Merrill) through direct somatic embryogenesis from the immature embryonic shoot tip. In Vitro Cell Dev Bio - Plant 46: 265273.

Manavalan, L.P., S.K. Guttikonda, L.S. Tran and H.T. Nguyen. 2009. Physiological and molecular approaches to improve drought resistance in soybean. Plant Cell Physiol., 50(7): 1260-1276.

Park, H.J., T.R. Kwon, K.H. Kim, T.S. Kim, Y.H. Park and Y.H. Kim. 2004. Effects of explants source, media and growth regulators on shoot regeneration of soybean (Glycine $\max$ (L.) Merr.) in Vitro. Korean J. Breed., 36(2): 71-75.

Paz M M, H Shou, Z Guo, Z Zhang, A K Banerjee, KWang (2004) Assessment of conditions affecting Agrobacteriummediated soybean transformation using the cotyledonary node explant. Euphytica 136: 167-179.

Radhakrishnan R, and Ranjithakumari B D (2007). Callus induction and plant regeneration of Indian soybean (Glycine $\max (\mathrm{L}$.$) Merr. cv. \mathrm{CO}_{3}$ ) via half seed explant culture. Journal of Agricultural Technology, 3: 287-297.

Yan B, M.S. Srinivasa Reddy, G B Collins, R D Dinkins. 2000. Agrobacteium tumefaciens-mediated transformation of soybean [Glycine max (L.) Merrill.] using immature zygotic cotyledon explants. Plant Cell Rep: 19: 10901097.

Zeng P, D A Vadnais, Z Zhang, J C Polacco (2004) Refined glufosinate selection in Agrobacterium-mediated transformation of soybean [Glycine max (L.) Merrill]. Plant Cell Rep. 22: 478-482.

\section{How to cite this article:}

Rathod, B.U., N.R. Dattagonde, M.P. Jadhav and Behre, P.P. 2017. Effect of Different Growth Regulators on Soybean (Glycine max L.) Regeneration. Int.J.Curr.Microbiol.App.Sci. 6(11): 2726-2731. doi: https://doi.org/10.20546/ijcmas.2017.611.321 